\title{
Highlights of Streptomyces genetics
}

\author{
David A. Hopwood ${ }^{1}$
}

Received: 8 January 2019 / Revised: 6 February 2019 / Accepted: 6 February 2019

(c) The Genetics Society 2019

\begin{abstract}
Sixty years ago, the actinomycetes, which include members of the genus Streptomyces, with their bacterial cellular dimensions but a mycelial growth habit like fungi, were generally regarded as a possible intermediate group, and virtually nothing was known about their genetics. We now know that they are bacteria, but with many original features. Their genome is linear with a unique mode of replication, not circular like those of nearly all other bacteria. They transfer their chromosome from donor to recipient by a conjugation mechanism, but this is radically different from the E. coli paradigm. They have twice as many genes as a typical rod-shaped bacterium like Escherichia coli or Bacillus subtilis, and the genome typically carries 20 or more gene clusters encoding the biosynthesis of antibiotics and other specialised metabolites, only a small proportion of which are expressed under typical laboratory screening conditions. This means that there is a vast number of potentially valuable compounds to be discovered when these 'sleeping' genes are activated. Streptomyces genetics has revolutionised natural product chemistry by facilitating the analysis of novel biosynthetic steps and has led to the ability to engineer novel biosynthetic pathways and hence 'unnatural natural products', with potential to generate lead compounds for use in the struggle to combat the rise of antimicrobial resistance.
\end{abstract}

\section{Introduction}

The Genetical Society, or 'Gen. Soc.' as we always used to call it, played a key role in my development as a geneticist. I gave offered papers at meetings through the 1960s and 1970s, was Junior Secretary (1970-1973) and then Senior Secretary (1973-1975), before having the honour to be President in 1984-1987. It is therefore a pleasure to write a short memoir in this volume marking the Society's centenary. Heredity has not been a major host for original papers pushing back the frontiers of microbial genetics, so my aim is briefly to introduce Streptomyces genetics to readership of the journal unfamiliar with it by outlining a little of its origins, followed by vignettes chosen to illustrate selected aspects of the subject in a little more detail. If any budding researchers are motivated to take an interest in the field by reading this article I shall be well satisfied.

David A. Hopwood

david.hopwood@jic.ac.uk

1 Department of Molecular Microbiology, John Innes Centre, Colney Lane, Norwich NR5 7UH, UK

\section{Origins}

Graduating in botany in the University of Cambridge in 1954, I looked for an interesting $\mathrm{PhD}$ project. Harold Whitehouse, lecturer in genetics in the Botany School, farsightedly predicted that the young science of microbial genetics was on the verge of a bright future. The Watson and Crick paper on the structure of DNA had come out from the Cavendish Laboratory across the road during my final year and it was abundantly clear that discoveries about the nature of the gene, genetic recombination and the basics of gene expression made with any tractable experimental system were likely to be generally applicable to all forms of life. Microbes, with their short life cycles and convenience of laboratory culture in huge populations, were prime subjects for pushing the boundaries.

Research on two fungal species, Neurospora crassa and Aspergillus nidulans, had already made striking advances, exploiting their known sexual life cycles and their growth on simple defined media, allowing the isolation of auxotrophic mutants, each blocked at a defined step in a nutrient's biosynthesis; Beadle and Tatum's 'one gene one enzyme' proposal (Beadle and Tatum 1941) was the most seminal discovery to date. Bacterial genetics, on the other hand, was still in a confused state. Genetic transformation of the pneumococcus had been discovered as early as 1928 
(Griffith 1928), and the 'transforming principle' was identified as DNA in 1944 (Avery et al. 1944). Conjugation in Escherichia coli came in 1946 (Lederberg and Tatum 1946), and transduction by a bacteriophage in Salmonella typhimurium in 1952 (Zinder and Lederberg 1952). These three modes of gene transfer were bizarrely different from each other. Conjugation most closely resembled mating in eukaryotes in requiring the intimate contact of two parental organisms or cells, whereas the other two processes did not: DNA was transferred either naked or enclosed in a bacterial virus from a donor that had no contact with the recipient. Moreover, it turned out that, even in the case of conjugation, DNA transfer from a donor to a recipient was hardly ever complete. There was thus a gulf between eukaryotes, including fungi, with a regular life cycle that included the fusion of a complete (haploid) set of chromosomes from each parent, followed by meiosis in which crossing over and re-assortment of chromosomes produced new genotypes, versus bacteria with the transfer of only a partial genome to produce a 'merodiploid', which went on to generate a limited extent of genetic recombination. But who knew what further strange genetic behaviours bacteria might be capable of?

Against this background, Lewis Frost, Harold Whitehouse's second-in command, suggested that I could see what kind of genetic novelties might exist in the actinomycetes. These microbes, largely inhabiting the soil and giving it its earthy odour, but also including pathogens like Mycobacterium tuberculosis, had been an enigma from a phylogenetic point of view ever since the discovery of their first representatives in the 1870s. Usually filamentous like fungi, rather than unicellular like known bacteria, but with much smaller dimensions than typical fungi (Fig. 1), were they 'senior bacteria' or 'junior fungi' (in the later words of Bill Hayes, one of the pioneers of E. coli genetics, when he introduced my paper at a Society for General Microbiology meeting) or were they an intermediate group? If the last, could their genetics throw up a new paradigm that might bridge the bacteria-fungi divide? Although the most studied actinomycetes, members of the genus Streptomyces, were becoming increasingly famous as producers of medically important antibiotics such as streptomycin, neomycin and tetracycline, largely due to the dogged work of Selman Waksman in the 1920s and '30s, who kept their study alive in the pre-antibiotics era (Waksman 1954), no serious genetic studies had been reported by 1954 . I therefore set out on my $\mathrm{PhD}$ to try to fill the gap.

Following the trail blazed by Joshua Lederberg and Edward Tatum when they discovered genetic recombination in $E$. coli, I isolated auxotrophic mutants, grew two differently marked strains together and looked for prototrophic recombinants as evidence of some kind of gene exchange. As in the early $E$. coli experiments, recombinants occurred

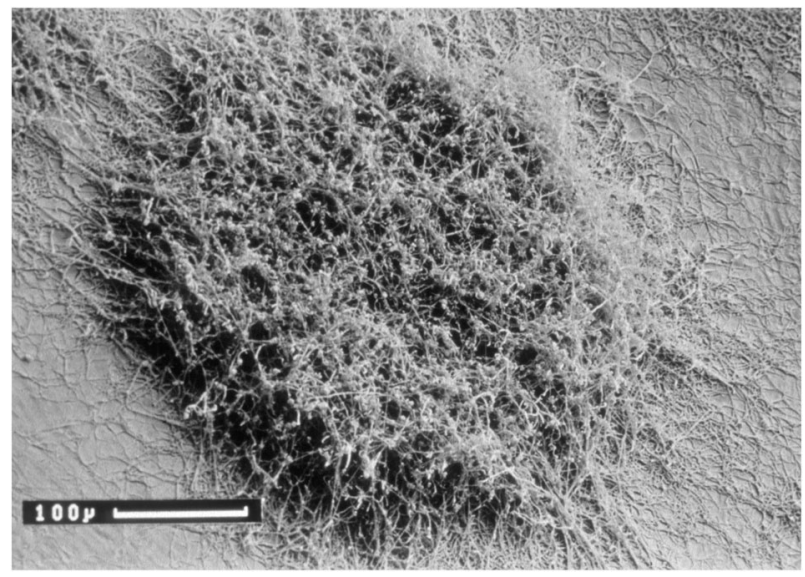

Fig. 1 Scanning electron micrograph of a colony of Streptomyces lividans growing on an agar plate in the laboratory. At the edge of the colony, hyphae of the substrate mycelium are foraging for nutrients on the surface of the medium and burrowing into it, while in the central regions the aerial hyphae are beginning to produce spores. From Figure 6.01 of Hopwood (2007), reproduced by permission of Oxford University Press

at a low frequency, only detectable by the ability to select them on a medium devoid of the specific nutrients required by the auxotrophic parents. Moreover, in crosses involving multiply marked strains, the recovery of recombinants carrying presumed recessive alleles from both parents ruled out a simple fusion process to yield the equivalent of the wellknown heterokaryosis in filamentous fungi such as $A$. nidulans; genuine recombination must have occurred. And genotypes that would have required the transfer of any given pair of markers suggested a conjugation-type event capable of combining extensive genome segments from both parents, rather than the transfer of short genomic fragments characteristic of transformation or transduction. We shall see later how this turned out to be true - and interestingly different from any process hitherto known in bacteria or any other microorganism.

As so often occurs in science, a timely idea strikes in more than one place. As I was getting my first results, it became clear that I was not alone in my search for genetic recombination in Streptomyces. At least one study, led by none other than Josh Lederberg, had been moved by similar considerations to my own, while three others, in Rome, Moscow and Rutgers New Jersey, were motivated by the idea, first propounded by Guido Pontecorvo, the pioneer of Aspergillus and Penicillium genetics and discoverer of the parasexual cycle as a means of generating recombinants in fungi without a regular sexual cycle, that the fermentation industry ought to be using the power of genetic recombination to develop high-yielding antibiotic-producing strains of fungi and actinomycetes, rather than relying simply on random mutation and selection, even though the latter was being relatively successful in increasing yields. 


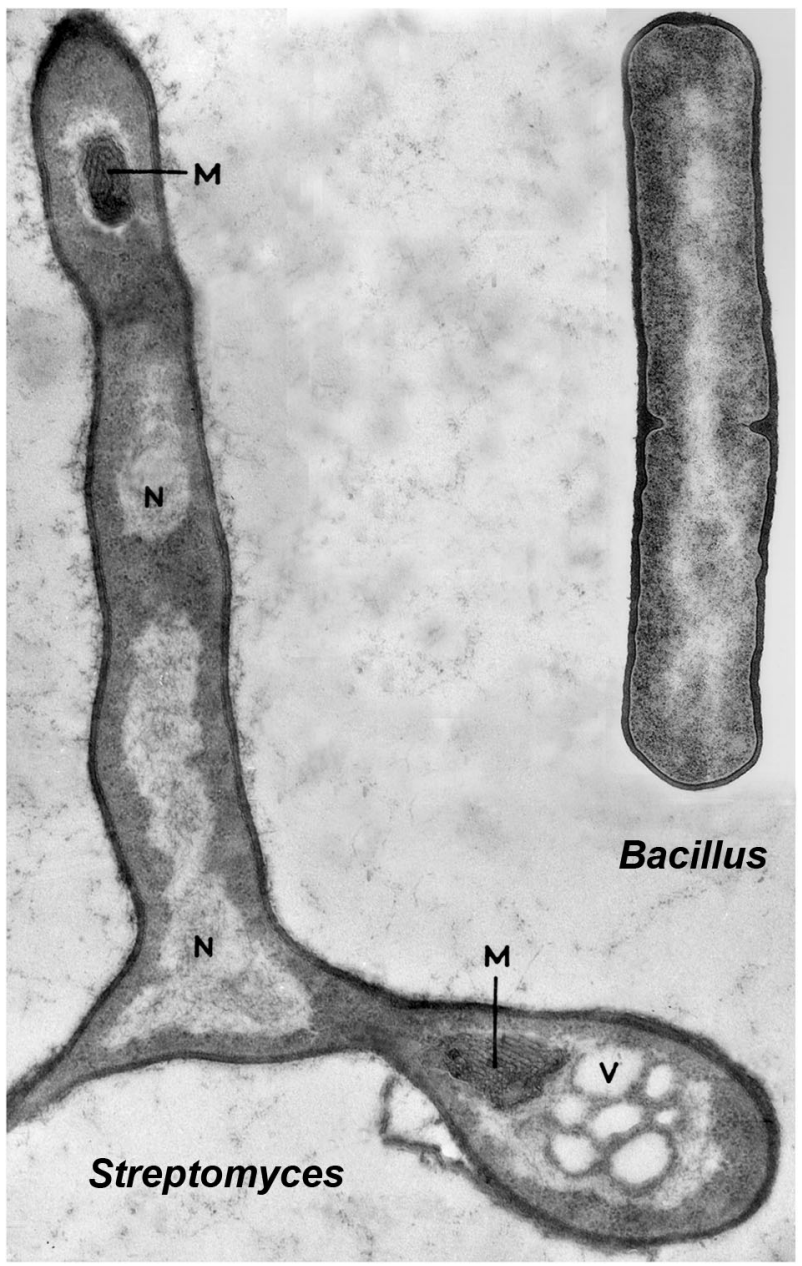

Fig. 2 Electron micrographs of thin sections of Streptomyces coelicolor and Bacillus subtilis showing the very similar cellular architecture of these two prokaryotes. $(\mathrm{V}=$ vacuoles left when storage compounds in the germinating spore have disappeared; $\mathrm{N}=\mathrm{DNA}$ of the genome - note the absence of a nuclear envelope separating it from the cytoplasm, $\mathrm{M}=$ mesosomes - membranous bodies carrying out the functions of eukaryotic mitochondria (these are also found in bacilli but not seen clearly in this section). From Figure 3.06 of Hopwood (2007), reproduced by permission of Oxford University Press

It was the publication in Nature by Giuseppe Sermonti and his wife Isabella Spada-Sermonti at the Istituto Superiore di Sanità in Rome (Sermonti and Spada-Sermonti 1955) that appeared first and, to my shock, described results identical to my own unpublished work and even with a strain of Streptomyces coelicolor, the same species that I had chosen! We had both picked this organism because it produced a beautiful blue pigment, actinorhodin, which we thought might eventually make a useful genetic marker, just as pigment mutants had been key to the development of Aspergillus nidulans genetics. As we shall see later, it was a prophetic choice because, being an antibiotic, actinorhodin provided a crucial entry into the world of antibiotic genetics and its manipulation.
After a brief publication of my own results, extending them to the development of a method of constructing a linkage map of the organism (Hopwood 1957, 1959), I collaborated with Giuseppe and Isabella in Rome, before they moved on to other topics, while the other groups also abandoned the field after a few publications. Thus, soon after moving to Pontecorvo's department in Glasgow in 1960, I was virtually the only protagonist of Streptomyces genetics until others joined my group, which became larger after we moved to the John Innes Institute (now Centre) in 1968. From then on, the field widened enormously, with numerous groups around the world making pioneering advances

Enough of the early history, except for one fundamental discovery. Soon after starting my PhD I was lucky enough to meet Audrey Glauert, of the Strangeways Laboratory in Cambridge, one of the pioneers in the study of bacterial structure by the newly developed technique of electron microscopy of thin sections. We struck up a fruitful collaboration and discovered that the cellular organisation of $S$. coelicolor as revealed by this technique closely resembled that of bacilli and other bona fide bacteria (Fig. 2), most notably in lacking a nuclear envelope; their DNA was 'naked' in the cytoplasm, so they were prokaryotes, not fungi, and not obviously an intermediate group (Glauert and Hopwood 1959). This conclusion was slow to be universally accepted, but doubt was put to rest for the vast majority of scientists when Carl Woese's ground-breaking phylogenetic approach, based on $16 \mathrm{~S}$ ribosomal RNA sequences, placed the actinomycetes firmly among the Gram-positive bacteria. (Ironically, his analysis did indeed reveal an 'intermediate' group, but these were the Archaea, not the actinomycetes - Woese and Fox 1977.)

I will devote the rest of this article to a brief account of some completely different aspects of actinomycete genetics, two largely of academic interest, and reflecting my early motivation to see what kind of gene exchange mechanisms these organisms might have evolved and the structure of their genomes, and the third on how genetic studies have illuminated the chemistry of natural products, notably antibiotics, with obvious possibilities for application. There have been many other fascinating areas of study, perhaps most importantly the analysis of the developmental cycle of these morphologically complex bacteria (Bush et al. 2015; Flärdh and Buttner 2009), but this is not meant as a comprehensive review of Streptomyces genetics. Much more information, especially about the history of the subject up to 2007, can be found in my book Streptomyces in Nature and Medicine: The Antibiotic Makers (Hopwood 2007), and of course there are inumerable recent reviews of different aspects of the field by experts in those areas. 


\section{Mating in Streptomyces: a new paradigm}

That conjugation in E. coli depended on a mechanism fundamentally different from the familiar sexual processes of eukaryotes became apparent through the pioneering work of Bill Hayes (Hayes 1953) and of Joshua Lederberg and his collaborators, who proposed the necessity for an extrachromosomal element, which Lederberg named a plasmid (Lederberg 1952), for the fertility of crosses between parental strains: hence its designation as the F factor. Strains carrying the plasmid free in the cytoplasm $\left(\mathrm{F}^{+}\right.$strains) donated the plasmid at high frequency to $\mathrm{F}^{-}$strains and transferred chromosomal genes when the $\mathrm{F}$ factor was integrated into the chromosome, in Hfr strains. Further evidence of the novelty of DNA transfer between donor and recipient came from the Pasteur Institute group of François Jacob and Elie Wollman in their famous 1958 interrupted mating experiment, which showed that chromosome transfer promoted by the $\mathrm{F}$ factor when integrated into the chromosome of the donor was progressive, taking an hour and a half for complete transfer as a limiting case; nearly always conjugation was spontaneously interrupted before completion (Jacob and Wollman 1961). Many studies later the picture emerged of DNA transfer in single-stranded form, through the agency of a mating pilus, the whole apparatus, including pilus synthesis and assembly, as well as DNA handling and all the other functions needed for successful mating required the products of about $30 \mathrm{tra}$ genes in a single giant operon covering $40 \mathrm{~kb}$ (Frost et al. 1994).

Our early studies implicated plasmids in genetic recombination in Streptomyces (Hopwood et al. 1973) but it was a huge surprise to discover, when some of the first Streptomyces plasmids were physically isolated and analysed by deletion and insertion experiments, that a region of only about $2 \mathrm{~kb}$ was all that was needed for conjugal transfer, later narrowed down to a single tra gene (Kieser et al. 1982). Clearly the E. coli paradigm, which had become the fall-back explanation for bacterial mating in general, did not apply. Furthermore, a second genetic region on the plasmid, named spd, for 'spread', was proposed to be responsible, not for DNA transfer between mating hyphae - the role of the tra gene - but for migration of plasmid copies within the recipient mycelium to populate hyphal compartments far from the original point of contact between the parents (Kieser et al. 1982). This would clearly be adaptive for a plasmid of a filamentous organism in the soil environment, where the mycelium grows thinly through the air spaces and chance contacts between colonies would be sporadic; in this way a plasmid could become present throughout the recipient mycelium, and eventually in the spores that it produced.

How can a single tra gene lead to plasmid transfer between hyphae, and how do the spd gene products work? A crucial observation was that the tra gene product - now called TraB - shows a similar domain structure to proteins that promote the movement of double-stranded DNA across closing septal boundaries in other bacteria, notably from the Bacillus subtilis mother cell into the developing endospore compartment (SpoIIIE) and during the division of bacteria such as E. coli into daughter cells (FtsK), using the energy provided by ATP hydrolysis (Vogelmann et al. 2011). That DNA is indeed transferred in double-stranded form in Streptomyces was later demonstrated in an ingenious experiment (Possoz et al. 2001).

More than anyone else, Günther Muth and his group in Tübingen have built up our current picture of the roles of the tra and spd genes in inter- and intra-mycelial plasmid transfer in Streptomyces, based on a series of elegant studies over many years; there is a timely review of progress and of unanswered questions about this remarkable process (Thoma and Muth 2016). They showed that the TraB protein inserts itself into the cell membrane in the form of a hexamer, forming a ring with a 3-nm pore through which double-stranded DNA could easily pass once the cell walls of the mating hyphae had coalesced, presumably by the breaking and re-making of crosslinks in the peptidoglycan. Fluorescence microscopy showed such complexes to occur on the lateral walls of the hyphae, so plasmid transfer would occur when two mycelia happened to grow alongside each other.

What about intra-mycelial spreading of plasmid copies within the recipient mycelium and the role of the Spd gene products in this process, unique to the actinobacteria? Unlike the single TraB protein, which has very similar domain architecture in all examples studied, Streptomyces plasmids typically carry several $s p d$ genes needed for the spreading process and their products vary in domain structure from one plasmid to another. Moreover, they show no useful homology with other gene products of known function. Nor do they carry recognisable molecular motor domains. Thus, Muth and his group have concluded that DNA transfer across the septa that divide the Streptomyces mycelium into compartments at irregular intervals would require a complex of Spd and TraB proteins.

The transfer of chromosomal DNA by Streptomyces plasmids is of course a crucial phenomenon for the host, and progress has been made in understanding it, but I do not propose to cover it here. See Thoma and Muth (2016) and Pettis (2018) for recent reviews, 


\section{The Streptomyces chromosome is linear with a unique mode of replication}

In my early struggles to understand the process of genetic recombination in $S$. coelicolor I was obsessed with the question of its genome architecture. Ever since Jacob and Wollman's conclusion, from their interrupted mating experiment, of a circular chromosome in E. coli, confirmed by John Cairns' classic autoradiograph experiment (Cairns 1963), circularity of bacterial chromosomes had been almost assumed as a rule. By genetic analysis I showed a single circular linkage map in S. coelicolor (Hopwood 1965) but, as pointed out by Stahl and Steinberg (1964), map circularity is an inevitable consequence of crossingover in a merodiploid. In an experiment involving the analysis of a population of partially heterozygous 'heteroclones' arising from crosses between parents carrying closely linked markers, I went on to conclude that the genome was either circular, or linear but without constant genome ends, as in bacteriophages T2 and T4 (Hopwood 1966). It was many years later that Carton Chen and his group in Taipei showed, in an elegant physical analysis, that the chromosome of Streptomyces lividans, a very close relative of $S$. coelicolor, is in fact linear with ends at a constant position (Lin et al. 1993), and there is no doubt that this applies to $S$. coelicolor too. Since the precise structure of the heteroclones is unknown, and they have not been amenable to physical analysis, there is still no way of reconciling my earlier experiment with this conclusion, but non-covalent association between the two ends of the chromosome is a possibility.

Owing to the way that double-stranded DNA is replicated in all organisms, with continuous replication of one strand and discontinuous replication of the other using a succession of RNA primers, linear chromosomes present a problem. Most bacteria have solved the problem by avoiding DNA ends, and eukaryotes cope with the loss of sequences when the last RNA primer is removed, by their complex telomere apparatus; so how does Streptomyces manage? Elegant studies by Stan Cohen's group and by Carton Chen's have revealed a completely novel mechanism. Replication occurs bidirectionally from a centrally located oriT, as in E. coli, and the gap left at either end of the chromosome when the last RNA primer is removed is infilled by priming from special 'telomere' proteins covalently bound to the 5' ends, which recognise several palindromic sequences capable of forming stable hairpins (Qin and Cohen 1998, Yang et al. 2016); what a brilliant solution to a universal problem!

We may ask, however, why the Streptomyces chromosome has evolved to be linear when the replication problem could have been solved by circularity as in nearly all other bacteria. The Streptomyces genome is nearly twice the size of $E$. coli's, and every compartment of the mycelium contains a dozen or more copies, so perhaps the concatemers that would form during circular chromosome replication and recombination would form a tangle that would be hard to resolve. Yet, the genome can become circular by the deletion of the telomeres and joining of the two ends, either spontaneously or through genetic manipulation (Chen et al. 2002), and the resulting strains appear to grow and sporulate normally. Perhaps they would have a slight disadvantage in the natural habitat - and natural selection works on small differences in fitness.

\section{From novel colours to new compounds: the power of genetics to illuminate natural product chemistry}

In the mid-1970s the adoption of Streptomyces coelicolor as my chosen organism came into its own. It produces the blue antibiotic actinorhodin, so mutants blocked in its biosynthesis at different steps in the pathway could be recognised from their altered coloration by visual inspection of thousands of colonies growing on Petri plates. Brian Rudd classified a set of mutants into seven classes based on their colour or lack of it, as well as by co-synthesis experiments between pairs of mutants, and mapped a member of each class to the same short region of the chromosomal linkage map (Rudd and Hopwood 1979). He thus established two important facts about the genetic control of antibiotic biosynthesis that became the general rule: that the genes are on the main chromosome of the organism, rather than on a plasmid, and that they form a cluster. The former was particularly topical because there had been widespread speculation, based on several rather ambiguous results that failed to be followed up, that plasmid involvement in antibiotic biosynthesis might be a general rule. There are now well-established examples of actinobacterial plasmids carrying natural product gene clusters, and indeed our laboratory had shown that another S. coelicolor antibiotic, methylenomycin, was controlled by genes on a major sex plasmid (Wright and Hopwood 1976), but such examples are in a minority.

In a second pioneering step, Paco Malpartida (Malpartida and Hopwood 1984) cloned the entire actinorhodin cluster in a reversal of mutant isolation, by looking for blue colonies in a shotgun cloning of DNA from a wild-type strain into a colourless mutant. Transfer of the clone to another Streptomyces species resulted in the ability to produce actinorhodin, proving that the complete set of genes needed for its synthesis from primary metabolites was carried on a segment of DNA, later shown to bear a cluster of 22 adjacent act genes. From there it was a logical step to construct recombinants between strains making different members of the chemical class to which actinorhodin belongs, leading to production of the first 'hybrid' 


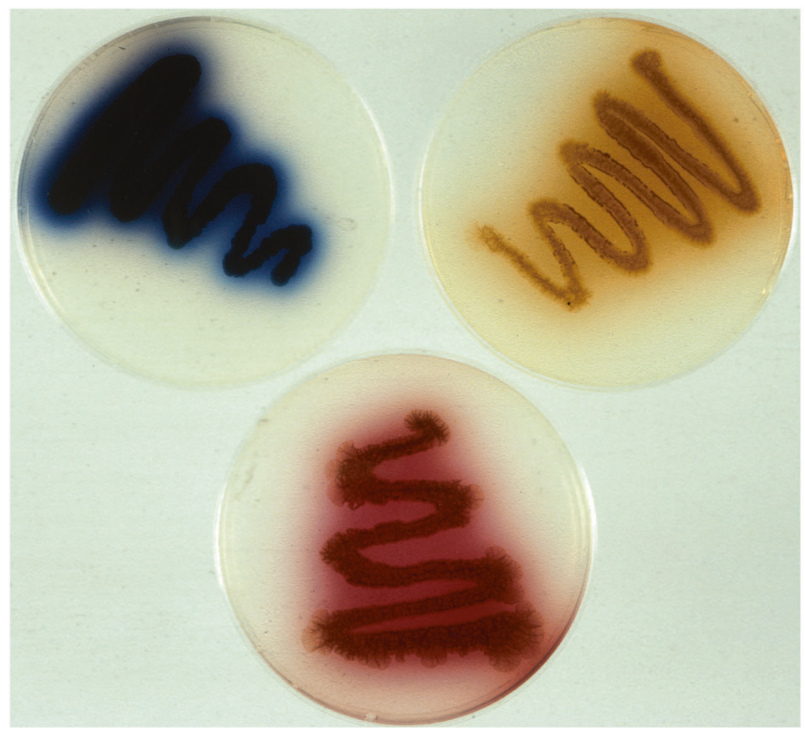

Fig. 3 Cultures of Streptomyces coelicolor making blue actinorhodin (top left), Streptomyces sp. AM-7161 making brown medermycin (top right) and a recombinant strain making purple mederhodin. Photograph courtesy of Helen Kieser

antibiotics (Hopwood et al. 1985). Once more, pigmentation was key: cloning of DNA from the producer of blue actinorhodin into a species making brown medermycin yielded purple 'mederhodin' (Fig. 3).

From then on, interest in generating 'unnatural natural products' by genetic engineering developed apace, most notably with the huge family of compounds known as polyketides, to which actinorhodin belongs together with important antibiotics like the tetracyclines, macrolides like erythromycin, polyenes such as nystatin, the antituberculosis drug rifamycin, the anthelminthic avermectin and many, many others. These molecules are put together by the linking of small carboxylic acid residues - acetate, propionate, butyrate, etc - to form long chains by processes analogous to those that synthesise fatty acids. It was already clear from biochemical studies that fatty acid synthases come in two flavours. One (Type I) was represented by the enzymes found in vertebrates, with the active sites required for the various steps in carbon chain assembly and modification being carried on a single multifunctional protein; the other class of synthase (Type II), found in E. coli and most other bacteria as well as plant plastids, consisted of separate proteins, each carrying a single active site and forming a non-covalent complex. It turned out from genetic studies that the synthases for aromatic polyketides like actinorhodin and tetracycline resemble Type II fatty acid synthases, and so novel compounds could be generated in a semi-rational way by mixing and matching complete genes from different Streptomyces species encoding various synthase subunits (McDaniel et al. 1993, 1995).
In contrast, the synthases for 'complex' or 'reduced' polyketides, represented by erythromycin, had a Type I organisation. The big surprise, however, was the finding from the sequence of the erythromycin gene cluster that the synthase is a giant protein with a distinct set of active sites (a module) for each round of chain assembly and modification, all organised as an assembly line colinear with the order of reactions required to build the complete carbon chain of the antibiotic (Donadio et al. 1990). In the case of erythromycin, the six 'modules' of active site 'domains' were found to be distributed over three proteins each carrying two modules (Fig. 4), while in other examples the enzyme consists of a set of proteins carrying one, two, three or more modules coming together to form the complete assembly line. This offered the possibility of exchanging whole modules between species or adding or subtracting modules to engineer novel molecules, but there was also the opportunity to exchange or mutate domains within modules in predictable ways. I'll just cite a couple of early examples from two of the pioneering groups: Bedford et al. (1996); Oliynyk et al. (1996).

Polyketides are not the only playground for natural product engineering. A huge number of important smallmolecule natural products are peptides. For many years the only known mechanism for their biosynthesis was by a nonribosomal process which turned out to proceed on giant synthetases analogous to the assembly lines for modular polyketide assembly, except that the building units for chain assembly were amino acid residues, very often including residues not found in ribosomally synthesised proteins, linked by peptide bonds, rather than carboxylic acid residues; such synthetases could be engineered by comparable techniques to generate novel compounds (Stachelhaus et al. 1996). Later it was discovered that a large group of peptide metabolites are in fact made on ribosomes as small segments of larger translation products, which are extensively modified post translationally to generate the end product. Genetic engineering of these RiPPs (Ribosomally synthesised and Post translationally modified Peptides) can thus include simple changes in the DNA of the gene encoding the primary sequence of the RiPP, along with the kind of techniques used for polyketides and non-ribosomal peptides (Hudson and Mitchell 2018).

In the early days of generating unnatural natural products by combinatorial biosynthesis there was a hope that the generation of libraries of novel compounds might produce a few with improved properties as clinical leads, and at least two biotech companies were founded to exploit this possibility: Kosan Biosciences in the San Francisco Bay Area and Biotica in Cambridge, England. However, it soon became apparent, in the shadow of big pharma's promotion of combinatorial chemistry to 
Fig. 4 a The assembly line model for the biosynthesis of erythromycin in

Saccharopolyspora (formerly Streptomyces) erythrea. b, c Details of the domain structure of two of the polyketide synthase proteins. AT, acyl transferase; ACP, acyl carrier protein; KS, ketosynthase; KR, ketoreductase; DH, dehydratase; ER, enoyl reductase. The unshaded domain at the right end of protein 3 in $\mathbf{a}$ is the thioesterase. From Figure 8.11 of Hopwood (2007), reproduced by permission of Oxford University Press
(A)

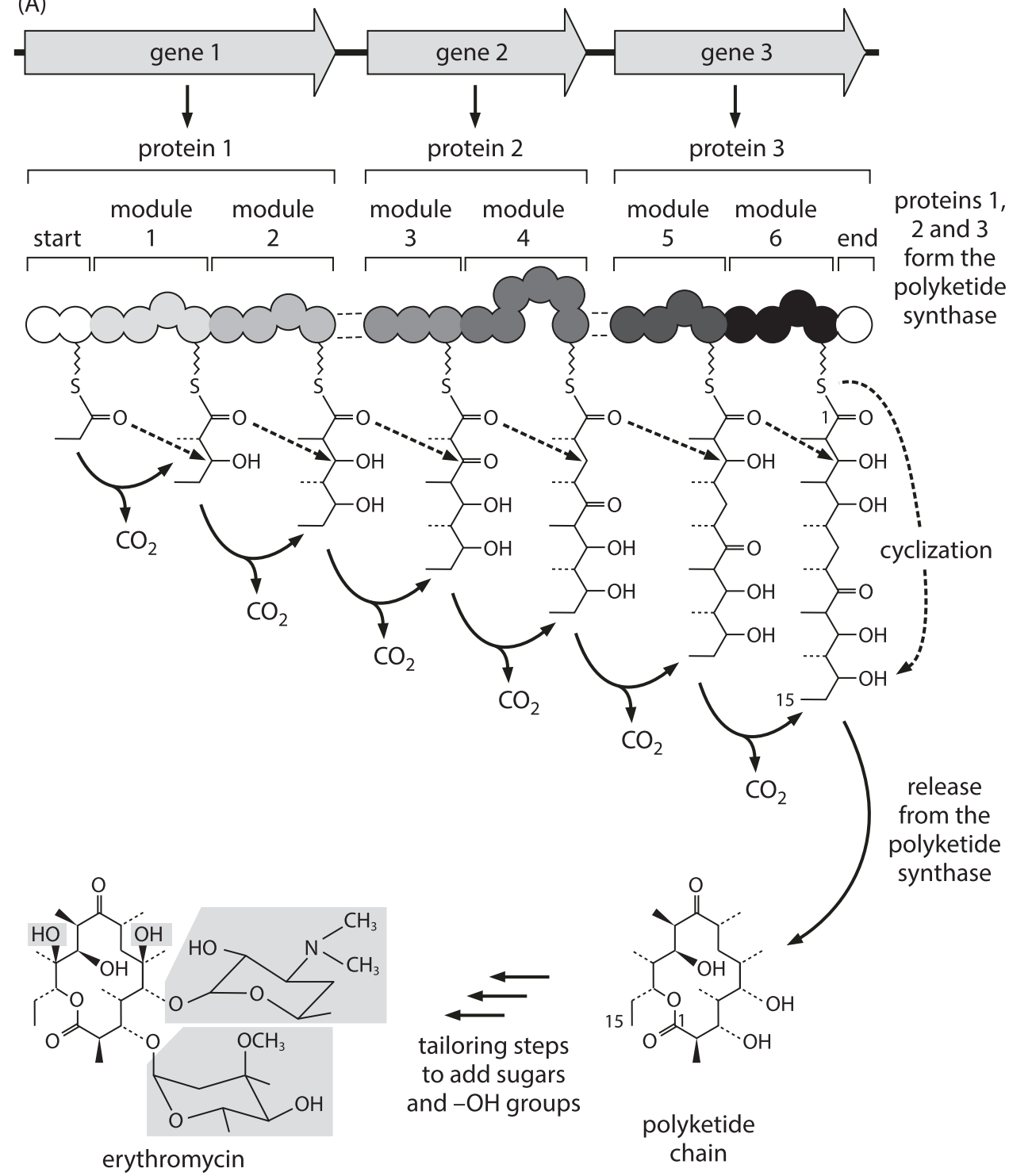

(B)

protein 1

(C)

protein 2

start module 1

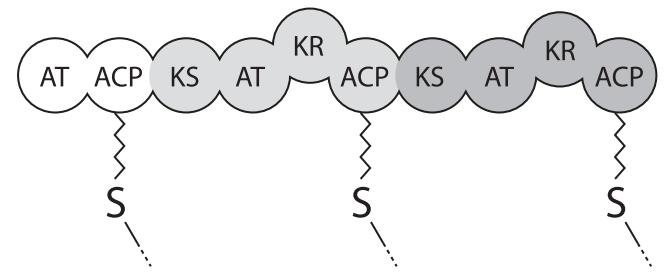

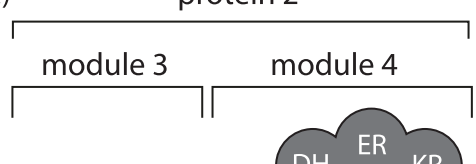

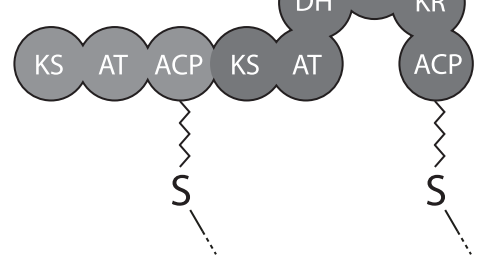

generate huge compound libraries and so replace the 'messy' hunt for natural products by traditional screening, that semi-random libraries were not the right goal for the genetic engineering approach. Combinatorial chemistry eventually failed spectacularly to produce compounds capable of being developed as drugs, but meanwhile biotech shifted towards a more focussed use of genetic strategies to carry out specific conversions, that could involve many synthetic steps in the chemical laboratory; see Ashley et al. (2006) for an example.

The emphasis was on the Type I modular polyketide synthases, because of the clear logic of the assembly line 
programming of the biosynthesis and the fact that many of the most clinically important compounds fell into this class. A major preoccupation, however, was the reduced titre of most of the products of engineered synthases, attributable to such factors as the 'docking' of the protein subunits of the recombinant synthase and recognition of unnatural substrates passed from an upstream to a downstream module. Similar problems were found to bedevil the engineering of non-ribosomal peptide synthetases.

There is now a huge literature describing and reviewing the genetic engineering of polyketide and peptide biosynthesis to generate novel compounds - far too much for a retired academic like me to keep up with. Here are a few recent reviews: Kalkreuter and Williams (2018); Klaus and Grininger (2018); Winn et al. (2016). Several authors have emphasised the need to ally combinatorial biosynthesis with synthetic biology: Kim et al. (2015); Weissman (2016). In one interesting example, natural genetic recombination has been used to aid the evolution of modular gene clusters: Wlodek et al. (2017). While the material for most studies has been the pathways leading to antibiotic compounds, a couple of promising examples of Streptomyces genetic manipulation have described production of an optimised cyclophilin inhibitor of chronic viral infection (Hansson et al. (2015) and of short-chain ketones as additives to increase the octane of petrol (Yuzawa et al. (2018).

Perhaps the most important turning point in the study of Streptomyces genetics was the sequencing and annotation of the complete genome of $S$. coelicolor at the Sanger Institute (Bentley et al. 2002). Begun in 1997 and taking four yours and nearly 2 million pounds to complete in those days, it revealed nearly 8000 genes (Fig. 5) - twice as many as in $E$. coli and considerably more than in the only eukaryotic microbe sequenced to date, the yeast Saccharomyces cerevisiae - throwing light on all aspects of the biology of the organism and opening innumerable lines of research (Chater 2016). Most relevant to the present account, there appeared to be more than 20 gene clusters capable of directing the biosynthesis of 'secondary' or 'specialised' metabolites, including antibiotics and pigments as well as many compounds whose possible functions could not be predicted. Three chromosomal gene clusters encoding antibiotic biosynthesis were already known, but the new discovery indicated that the genome contained the information to produce many more potentially novel molecules whose biosynthesis was likely to require stimuli - chemical, physical or biological - encountered in the soil environment but not under typical laboratory conditions. A second complete Streptomyces genome sequence, that of $S$. avermitilis (Ikeda et al. 2003), conducted in parallel at the Kitasato Institute in Tokyo, revealed 30 such gene clusters.

It is difficult to overestimate the importance of these findings in relation to natural product discovery since it

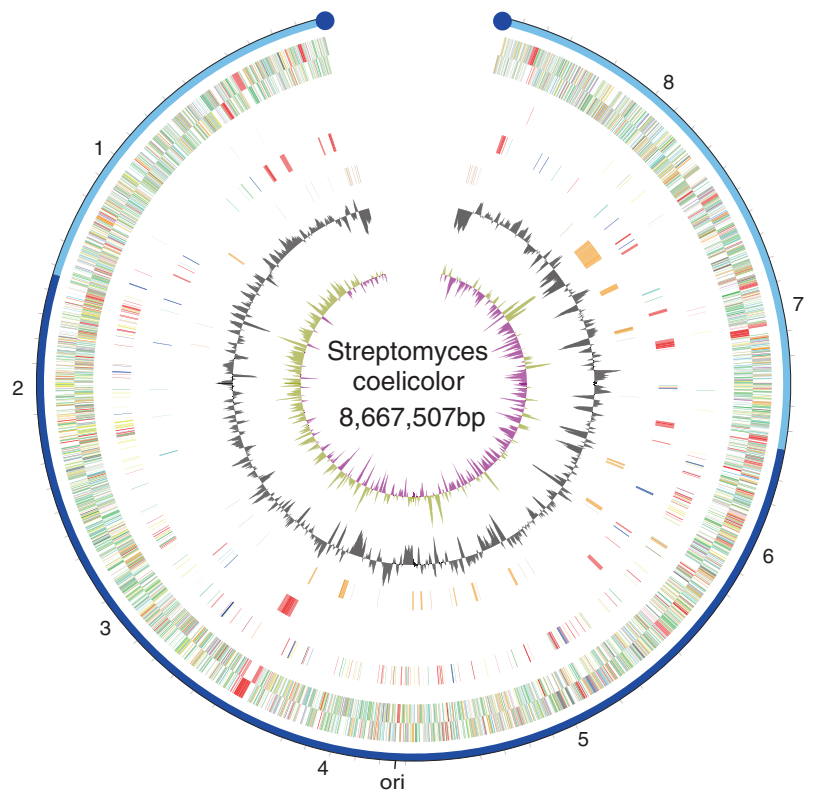

Fig. 5 Circular representation of the Streptomyces coelicolor chromosome showing the telomere proteins as small blue circles and the centrally located origin of replication. The outer scale is numbered anticlockwise in megabases. The other circles show various features of the genome, circles 1 and 2 from the outside in representing all the genes on the two strands of the DNA. From Bentley et al. (2002)

overturned the prevailing thinking in big pharma that the Golden Age of antibiotic discovery was well and truly over and that hardly any new and useful compounds would be found by exploiting natural products. The challenge remains, however, as to how to wake up these sleeping gene clusters in realistically scalable ways to reveal their products. This is an active area of research. Meanwhile, with the cost of DNA sequencing in precipitous decline, thousands of actinobacterial genome sequences have been obtained, with little published evidence that a plateau has been reached in the chemical novelty they encode. And total DNA sequencing has become the go-to way to isolate gene clusters for analysis and manipulation. The same has become true for filamentous fungi (Keller 2018), the other group of microorganisms long known to be a source of valuable natural products - think penicillin - but more surprisingly in groups of bacteria not previously expected to be happy hunting grounds for novel chemistry, including Gram-negative bacteria like the myxobacteria, pseudomonads and cyanobacteria (Masschelein et al. 2017).

It remains to be seen how successful the legacy of Streptomyces genetics will turn out to be in aiding the struggle to find clinically important antibiotics in these times when scientists, clinicians and politicians are predicting a possible end to the treatment of life-threatening infections, and even jeopardising routine operations like joint and organ replacements, because of the rise of antimicrobial resistance. One thing is clear, however: natural 
product chemistry has been revolutionised by the ability to clone, sequence, analyse and manipulate the genes that encode the enzymes responsible for the most amazing chemistry that Nature has invented. 'Chemistry by genetics' is now a set of enormously powerful tools for making new molecules and for helping to elucidate unexpected chemistry in natural product biosynthesis - see Leipoldt et al. (2017) for an example.

Acknowledgements I am grateful to Barrie Wilkinson of the John Innes Centre for helping me to make sense of the huge recent literature on the genetic manipulation of natural product biosynthesis.

\section{Compliance with ethical standards}

Conflict of interest The authors declares that he has no conflict of interest.

Publisher's note: Springer Nature remains neutral with regard to jurisdictional claims in published maps and institutional affiliations.

\section{References}

Ashley GW, Burlingame M, Desai R, Fu H, Leaf T, Licari PJ, Tran C et al. (2006) Preparation of erythromycin analogs having functional groups at C-15. J Antibiot 59:392-401

Avery OT, Macleod CM, McCarty M (1944) Studies on the chemical nature of the substance inducing transformation of pneumococcal types: induction of transformation by a deoxyribonucleic acid fraction isolated from pneumococcus type III. J Exp Med 79:137-158

Beadle GW, Tatum EL (1941) Genetic control of biochemical reactions in Neurospora. Proc Natl Acad Sci USA 27:499-506

Bedford D, Jacobsen JR, Luo G, Cane DE, Khosla C (1996) A functional chimeric modular polyketide synthase generated by domain replacement. Chem Biol 3:827-831

Bentley SD, Chater KF, Cerdeño A-M, Challis GL, Thomson NR, James KD, Harris DE et al. (2002) Complete genome sequence of the model actinomycete Streptomyces coelicolor A3(2). Nature 417:141-147

Bush MJ, Tschowri N, Schlimpert S, Flärdh K, Buttner MJ (2015) C-di-GMP signalling and the regulation of developmental transitions in streptomycetes. Nat Rev Microbiol 13:749-760

Cairns J (1963) The bacterial chromosome and its manner of replication. J Mol Biol 6:208-213

Chater KF (2016) Recent advances in understanding Streptomyces. F1000Research 5:2795. https://doi.org/10.12688/f1000research. 9534.1).

Chen CW, Huang CH, Lee HH, Tsai HH, Kirby R (2002) Once the circle has been broken: dynamics and evolution of Streptomyces chromosomes. Trends Genet 18:522-529

Donadio S, Staver MJ, McAlpine JB, Swanson SJ, Katz L (1990) Modular organization of genes required for complex polyketide biosynthesis. Science 252:675-679

Flärdh K, Buttner MJ (2009) Streptomyces morphogenetics: dissecting differentiation in a filamentous bacterium. Nat Rev Microbiol 7:36-49

Frost LS, Ippen-Ihler K, Skurray RA (1994) Analysis of the sequence and gene products of the transfer region of the $\mathrm{F}$ sex factor. Microbiol Rev 58:162-210
Griffith F (1928) The significance of pneumococcal types. J Hyg 27:113-159

Glauert AM, Hopwood DA (1959) A membranous component of the cytoplasm in Streptomyces coelicolor. J Biochem Biophys Cytol 6:515-516

Hansson MJ, Moss SJ, Bobardt M, Chatterji U, Coates N, GarciaRivera JA, Elmér E et al. (2015) Bioengineering and semisynthesis of an optimized cyclophilin inhibitor for treatment of chronic viral infection. Chem Biol 22:285-292

Hayes W (1953) The mechanism of genetic recombination in Escherichia coli. Cold Spring Harb Quant Biol 18:75-93

Hopwood DA (1957) Genetic recombination in Streptomyces coelicolor. J Gen Microbiol 16:ii-iii

Hopwood DA (1959) Linkage and the mechanism of recombination in Streptomyces coelicolor. Ann NY Acad Sci 81:887-898

Hopwood DA (1965) A circular linkage map in the actinomycete Streptomyces coelicolor. J Mol Biol 12:514-516

Hopwood DA (1966) Lack of constant genome ends in Streptomyces coelicolor. Genetics 54:1177-1184

Hopwood DA (2007) Streptomyces in Nature and Medicine: The Antibiotic Makers. OUP, New York, NY

Hopwood DA, Chater KF, Dowding JE, Vivian A (1973) Advances in Streptomyces coelicolor genetics. Bacteriol Rev 37:371-405

Hopwood DA, Malpartida F, Kieser HM, Ikeda H, Duncan J, Fujii I, Rudd BAM et al. (1985) Production of 'hybrid' antibiotics by genetic engineering. Nature 314:642-644

Hudson GA, Mitchell DA (2018) RiPP antibiotics: biosynthesis and engineering potential. Curr Opin Microbiol 45:61-69

Ikeda H, Ishikawa J, Hanamoto A, Shinose M, Kikuchi H, Shiba T et al. (2003) Complete genome sequence and comparative analysis of the industrial microorganism Streptomyces avermitilis. Nat Biotechnol 21:526-531

Jacob F, Wollman E (1961) Sexuality and the genetics of bacteria. Academic Press, New York, NY

Kalkreuter E, Williams GJ (2018) Engineering enzymatic assembly lines for the production of new antimicrobials. Curr Opin Microbiol 45:140-148

Keller NP (2018). Fungal secondary metabolism: regulation, function and drug discovery. Nat Rev Microbiol. epub ahead of print. https://doi.org/10.1038/s41579-018-0121-1.

Kim E, Moore BS, Yoon YJ (2015) Reinvigorating natural product combinatorial biosynthesis with synthetic biology. Nat Chem Biol 11:649-659

Kieser T, Hopwood DA, Wright HM, Thompson CJ (1982) pIJI01, a multi-copy broad host-range Streptomyces plasmid: functional analysis and development of DNA cloning vectors. Mol Gen Genet 185:223-238

Klaus M, Grininger M (2018) Engineering strategies for rational polyketide synthase design. Nat Prod Rep 35:1070-1081

Lederberg J (1952) Cell genetics and hereditary symbiosis. Physiol Rev 32:403-430

Lederberg J, Tatum EL (1946) Gene recombination in Escherichia coli. Nature 158:558

Leipoldt F, Santos-Aberturas J, Stegmann DP, Wolf F, Kulik A, Lacret R, Popadić D et al. (2017) Warhead biosynthesis and the origin of structural diversity in hydroxamate metalloproteinase inhibitors. Nat Commun 8:12

Lin Y-S, Kieser HM, Hopwood DA, Chen CW (1993) The chromosomal DNA of Streptomyces lividans 66 is linear. Mol Microbiol 10:923-933

Malpartida F, Hopwood DA (1984) Molecular cloning of the whole biosynthetic pathway of a Streptomyces antibiotic and its expression in a heterologous host. Nature 309:462-464

Masschelein J, Jenner M, Challis GL (2017) Antibiotics from Gramnegative bacteria: a comprehensive overview and selected biosynthetic highlights. Nat Prod Rep 34:712-783 
McDaniel R, Ebert-Khosla S, Hopwood DA, Khosla C (1993) Engineered biosynthesis of novel polyketides. Science 262:1546-1550

McDaniel R, Ebert-Khosla S, Hopwood DA, Khosla C (1995) Rational design of aromatic polyketide natural products by recombinant assembly of enzymatic subunits. Nature 375:549-554

Oliynyk M, Brown MJ, Cortés J, Staunton J, Leadlay PF (1996) A hybrid modular polyketide synthase obtained by domain swapping. Chem Biol 3:833-839

Pettis GS (2018) Spreading the news about the novel conjugation mechanism in Streptomyces bacteria. Environ Microbiol Rep 10:503-510

Possoz C, Ribard C, Gagnat J, Pernodet JL, Guerineau M (2001) The integrative element pSAM2 from Streptomyces: kinetics and mode of conjugal transfer. Mol Microbiol 42:159-166

Qin Z, Cohen SN (1998) Replication at the telomeres of the Streptomyces linear chromosome. Mol Microbiol 28:893-903

Rudd BA, Hopwood DA (1979) Genetics of actinorhodin biosynthesis by Streptomyces coelicolor A3(2). J Gen Microbiol 114:35-43

Sermonti G, Spada-Sermonti I (1955) Genetic recombination in Streptomyces. Nature 176:121

Stachelhaus T, Schneider A, Marahiel MA (1996) Engineered biosynthesis of peptide antibiotics. Biochem Pharmacol 52:177-186

Stahl FW, Steinberg CM (1964) The theory of formal genetics for circular maps. Genetics 50:531-538

Thoma L, Muth G (2016) Conjugative DNA transfer in Streptomyces, a mycelial organism. Plasmid 87-88:1-9

Vogelmann J, Ammelburg M, Finger C, Guezguez J, Linke D, Flötenmeyer M, Stierhof YD et al. (2011) Conjugal plasmid transfer in Streptomyces resembles bacterial chromosome segregation by FtsK/SpoIIIE. EMBO J 30:2246-2254

Waksman SA (1954) My Life with the Microbes. Simon and Schuster, New York, NY

Weissman KJ (2016) Genetic engineering of modular PKSs: from combinatorial biosynthesis to synthetic biology. Nat Prod Rep 33:203-230

Winn M, Fyans JK, Zhuo Y, Micklefield J (2016) Recent advances in engineering nonribosomal peptide assembly lines. Nat Prod Rep 33:317-347

Wlodek A, Kendrew SG, Coates NJ, Hold A, Pogwizd J, Rudder S, Sheehan LS et al. (2017) Diversity oriented biosynthesis via accelerated evolution of modular gene clusters. Nat Commun $8: 10$

Woese CR, Fox GE (1977) Phylogenetic structure of the prokaryotic domain: the primary kingdoms. Proc Natl Acad Sci USA 74:5088-5090

Wright LF, Hopwood DA (1976) Identification of the antibiotic determined by the SCP1 plasmid of Streptomyces coelicolor A3 (2). J Gen Microbiol 95:96-106

Yang CC, Tseng SM, Pan HY, Huang CH, Chen CW (2016) Telomere associated primase repairs truncated telomeres of Streptomyces. Nucl Acids Res 45:5838-5849

Yuzawa S, Mirsiaghi M, Jocic R, Fujii T, Masson F, Benites VT, Baidoo EEK et al. (2018) Short-chain ketone production by engineered polyketide synthases in Streptomyces albus. Nat Commun 9:8

Zinder ND, Lederberg J (1952) Genetic exchange in Salmonella. J Bacteriol 64:679-699 